\title{
O TEMPO COMO PROTAGONISTA EM ANNA DOS 6 AOS 18, DE NIKITA MIKHALKOV
}

Cristiane Moreira Ventura*

RESUMO: O presente estudo visa analisar como a atuação do tempo - cronológico (histórico) e subjetivo (memória) - aliado às imagens de arquivos, torna-se um forte elemento dentro da narrativa enquanto possível peça fundamental para a construção da mesma. Para exemplificar essas estratégias de utilização do tempo, analisarei o documentário Anna dos 6 aos 18 (1993) do cineasta russo Nikita Mikhalkov. Além de discutir as conotações da memória e autorreferencialidade e suas respectivas implicaturas dentro da construção da narrativa fílmica.

PALAVRAS-CHAVE: Documentário; Literatura comparada Material de arquivo; Narrativas de si; Tempo. *crisventura7@gmail.com

Mestranda em Estudos de Linguagens, Centro Federal de Educação Tecnológica de Minas Gerais (CEFET-MG).

ABSTRACT: This work aims to analyze how the action time (chronological and subjective), coupled with archival footage, becomes a strong element within the narrative whereas the cornerstone for the construction of it. To exemplify these time use strategies, I will analyze the documentary Anna from 6 to 18 (1993), directed by Russian filmmaker Nikita Mikhalkov. I'll also discuss the connotations of memory and self-referentiality, and their implication in the construction of filmic narrative.

KEYWORDS: Documentary; Comparative Literature: Archival material; Narrativesthemselves; Time. 
Hay detrás del tiempo del relato una lógica intemporal? [...] la tarea consiste em llegar a dar una descripción estructural de la ilusión cronológica; corresponde a la lógica narrativa dar cuenta del tiempo narrativo. Se podría decir, de otra manera, que la temporalidad no es sino una classe del relato

(del discurso).

Roland Barthes

O ato de narrar carrega em si a marca do tempo, seja por meio da própria palavra assinalada pela conjugação verbal, seja pela própria imersão aos acontecimentos, em que o narrador e o "interlocutor" conseguem compartilhar, vivenciar, recordar e sentir as marcas desse tempo, por ser ele representado pela memória ou mesmo por materiais de arquivo, vestígios ou provas dos acontecimentos.

No cinema, o tempo é "esculpido" no trabalho de montagem, através da duração das sequências e pela ordem dos acontecimentos que são inseridos ao longo da narrativa. Com objetivo de discutir como o tempo pode se tornar o elemento determinante de uma obra, tomarei como objeto de estudo o documentário Anna dos 6 aos 18, de 1993, dirigido pelo cineasta russo Nikita Mikhalkov.

O filme Anna dos 6 aos 18, produzido clandestinamente no período de censura que a Rússia vivenciou durante o socialismo, entre 1918 a 1991, retrata as mudanças ocorridas por meio da transformação política no modo de vida dos russos, inclusive na vida da própria filha do diretor: Anna.
Mikhalkov tem como dispositivo documentar a vida de sua filha, a proposta era filmar um rolo de filme por ano, durante fazendo a ela as mesmas perguntas: $\mathrm{O}$ que ela mais teme? O que ela mais quer? O que mais ama? O que menos gosta? Além do desenvolvimento da vida de Anna, o diretor criou outras camadas narrativas, como os acontecimentos políticos ocorridos entre 1979 a 1991, e cenas ficcionais de seu filme Alguns dias na vida de Oblomov (1979). As imagens selecionadas desse último são da infância de Oblomov, que vive durante o Império Czarista russo (monarquia estabelecida em 1547, com Ivan IV, sendo extinta em 1917 com a morte de Nicolau II e com a Revolução Russa), seu objetivo era comparar as duas infâncias para descobrir o que divergia e convergia desses diferentes momentos históricos. Ao partir da estrutura montada por Mikhalkov, pretendo analisar como as narrativas se entrecruzam dentro das dimensões que variam entre o público e privado, tempo cronológico (histórico) e tempo subjetivo (memória), e como esses se relacionam à noção de real (factual) e ficcional.

\section{AS DIMENSÕES DO AROUIVO E A MEMÓRIA}

Ao pensarmos no gênero documentário, é comum associarmos algumas práticas frequentes em sua realização, como: abordar algum fato real, trazendo à luz provas, documentos, registros, entrevistas e materiais de arquivo - estes podem ser público, privado, televisivo, pessoal, anônimo. 
Embora essas práticas de realização sejam comuns no documentário, atualmente podemos observar que não só o audiovisual tem explorado cada vez mais os recursos de materiais de arquivo, como a mídia e diversas formas de expressões artísticas têm se apropriado desse tipo de disparador. Mas o que seria o arquivo? Como conceituar um termo tão amplo, que pode abrigar diversos significados? Sobre a noção de arquivo, Jacques Derrida faz as seguintes colocações:

Não comecemos pelo começo nem pelo arquivo. Mas pela palavra "arquivo" - e pelo arquivo de uma palavra tão familiar. Arkhê, lembremos, designa ao mesmo tempo o começo e comando. Este nome coordena aparentemente dois princípios em um: o princípio da natureza ou da história, ali onde as coisas começam. [...] É bem verdade que o conceito de arquivo abriga em si mesmo esta memória do nome arkhê. Mas também se conserva ao abrigo desta memória que ele abriga: é o mesmo que dizer que a esquece. [...] De certa maneira, o vocábulo remete ao Arkhêno sentido nomológico, ao arkhedo comando. Como archivum ou archium latino [...] o sentido de arquivo, seu único sentido, vem para ele do arkeîongrego: inicialmente uma casa, um domicílio. ${ }^{1}$

DERRIDA. Mal de arquivo, p. 11 (grifo nosso).

Dessa forma, o diretor russo parte de sua origem, de sua casa, para realizar o filme, e em determinado momento de sua narração, ele recorda: "Para ser honesto, nesta época, em
1980, eu não sabia ainda que filme ia fazer. Eu sentia, intuitivamente, e claro, que podia ser um documento importante, embora não pudesse ver a sua forma". ${ }^{2}$ A proposta inicial seria filmar um rolo por ano fazendo as mesmas perguntas a sua filha.

Para Maurício Lissovsky, o arquivo possui cinco dimensões: a primeira seria a historiográfica; a segunda, a republicana; a terceira, a cartorial; a quarta, a cultual; e a quinta é a dimensão poética, a qual está relacionada ao perfume da Madeleine de Proust. $\mathrm{O}$ arquivo está relacionado à memória que "não é unidirecional, como sugere a noção de rememoração, mas se constrói em movimentos costurados entre o passado e o presente. Toda memória é bidirecional, pois o passado, na mesma medida, visa ao futuro". ${ }^{3}$ Assim, podemos observar que, em Anna dos 6 aos 18, Mikhalkov utiliza materiais de arquivos historiográficos e pessoais, para falar do passado e do tempo presente (ou futuro, a voz do narrador vem ao futuro em relação aquelas cenas). Já Walter Benjamin contrapõe essa noção da memória ser bidirecional ao afirmar que:

Não é que o passado lança luz sobre o presente ou que o presente lança sua luz sobre o passado; mas a imagem é aquilo em que o ocorrido encontra o agora num lampejo, formando uma constelação. Em outras palavras: a imagem é a dialética
2. Cf. MIKHALKOV, Nikita. Anna dos 6 aos 18 .

3. LISSOVSKY. Quatro + uma dimensões do arquivo, p. 61

$\begin{array}{lllllll}\text { EM TESE } & \text { BELO HORIZONTE } & \text { v. } 19 & \text { N. } 1 & \text { JAN.-ABR. } 2013 & \text { VENTURA. } 0 \text { tempo como protagonista em Anna dos } 6 \text { aos } 18 \text { [...] } & \text { P. } 262-275\end{array}$

Crítica Literária, outras Artes e Mídias 
4. BENJAMIN. Passagens, p. 504 (grifo nosso). na imobilidade. Pois, enquanto a relação do presente com o passado é puramente temporal e contínua, a relação do ocorrido com o agora é dialética - não é uma progressão, e sim uma imagem, que salta. Somente as imagens dialéticas são imagens autênticas (isto é: não arcaicas), e o lugar onde as encontramos é a linguagem. ${ }^{4}$

A ideia de uma "simetria" entre passado e presente (ou futuro) é idealizada, porém como afirma Benjamin, a memória seria esse lampejo, um momento que salta, algo que pode ser manifestado por meio de uma linguagem. Mikhalkov, ao juntar esses vários fragmentos de memória, constrói o filme como uma colcha de retalhos, recolhe diversos momentos, mas desenvolve uma estrutura cronológica linear (mesmo utilizando em alguns momentos o recurso de flash-back).

Para o historiador francês Didi-Huberman, a imagem de arquivo é algo indecifrável e pode gerar diversos efeitos de interpretações, ela precisa estar ancorada a outros elementos para ganhar algum sentido.

Em Anna dos 6 aos 18, Mikhalkov utiliza materiais de arquivo da TV, além de registrar imagens transmitidas e assistidas por sua filha Anna. Usa também materiais de arquivo pessoal (registros de sua filha) e privado de sua (imagens de sua família). Apesar de o diretor utilizar algumas imagens de arquivo já conhecidas mundialmente - e como imagens das
Olimpíadas de 1980; a imagem do manifestante em frente aos tanques de guerra na Praça da Paz Celestial, na China; imagens da queda do Muro de Berlim -, a montagem aliada ao texto, em voz-over do diretor, ganha uma dimensão nova, seguindo assim o pressuposto do cineasta alemão Harun Farocki: "Não é preciso buscar novas imagens, imagens nunca antes vistas, mas utilizar as imagens existentes de uma forma que elas se tornem novas". ${ }^{5}$ Dessa maneira, Mikhalkov, realiza uma montagem "mixada", polifônica, pois toma o que é do outro e mostra o que lhe é próprio, sua visão de mundo, para desconstruir o discurso originário da imagem e transformá-lo em seu próprio discurso, em sua narrativa.

A recepção e a produção de registro do "real" foram modificadas após o advento da psicanálise, devido, por exemplo, à “insuficiência da linguagem em referir-se ao real" ${ }^{\prime \prime}$ ou mesmo devido ao fato de que "o real precisa ser ficcionado para ser pensado"? Trazer à luz as próprias memórias, experiências vivenciadas e transformá-las em representações, em expressões artísticas, por meio de materiais de arquivo, poderia ser uma representação de um sentimento, como por exemplo, o sentido da falta ou da ausência de algo que está entre o visível e o dizível.
5. FAROCKI apud LINS, C.; REZENDE, L. O audiovisual contemporâneo e a criação com imagens de arquivo, p. 588.

6. SOUZA. Janelas indiscretas, p. 63.

7. RANCIĖRE A partilha do sensível, p. 58.

\section{Crítica Literária, outras Artes e Midias}




\section{O ESPAÇO E O TEMPO}

O filme inicia-se com um plano sequencia em "zoom out" de uma paisagem campestre, apresentando uma vasta horizontalidade, representando assim a grande extensão territorial que é a Rússia. O espaço mostrado é o ambiente onde vive a família do diretor Mikhalkov, esse plano poderia significar o distanciamento entre o diretor e o que ele deseja retratar, pois, na sequência posterior, escutamos, em voz-over, Mikhalkov em tom de nostalgia, narrar em um tempo em que não é aquele presente das imagens que são mostradas. Notamos tanto pelo uso do tempo verbal pretérito como pelo próprio depoimento que revela que levou treze anos para realizar o filme em questão. Neste plano, vemos imagens da pequena Anna, sentada em um banco decifrando suas primeiras palavras, ela lê lentamente as palavras do título de um livro de Léon Tolstoi: Anna Karenina, talvez seja essa a origem do nome da filha do diretor russo. Para compor essa atmosfera de algo do passado, vemos "planos detalhes" da pintura já gasta pelo tempo, teias de aranha junto ao parapeito da varanda. O diretor parece observar aquele tempo como algo distante, como um sonho, e declara que aquel tempo passou: “[...] a casa se foi, como a varanda onde tomávamos café, o banco, e cachorro, que minha filhinha corre atrás. Se foi também o império onde isto aconteceu. Ele também desapareceu”. Nesse momento, é possível identificar o primeiro entrecruzamento da história de vida, desse que se insere no filme, com a história do seu país, como também podemos inferir que o tempo da Rússia czarista de Tolstoi passou. A sequência posterior a esse pronunciamento apresenta imagens de arquivo de cunho institucional, retrata toda potência da União Soviética, imagens das Olimpíadas de 1980 e do Secretário Geral do Partido Comunista e presidente da URSS naquele momento: Leonid Brejnev. A partir desses diferentes tipos de registros, o diretor, no instante da montagem declara em voz-over de modo sincrônico a essas imagens: a segunda filmagem de Anna, em 1980, e confessa que, naquele momento, não sabia o que faria com aquelas imagens, sua proposta então passa a ser o questionamento dos medos e angústias de sua filha no decorrer dos anos.

Para situar-se de alguma forma na história da Rússia, o diretor conta um pouco sobre a origem de sua família. Quadros do avô pintor estão presentes nas paredes, assim como fotos de seus familiares, como de seu pai Sergey Mikhalkov, famoso escritor e poeta russo, autor do hino da União Soviética e do hino da Rússia. As informações sobre a importância cultural de seus familiares na União Soviética não é destacada pelo diretor, ele se atém a contar um pequeno acontecimento da infância de seu pai. Podemos compreender que essa escolha do diretor em não abordar muito essas questões seja pela sua divergência com o comunismo. Mikhalkov parece identificar-se mais com a visão política e postura de sua mãe,

Crítica Literária, outras Artes e Mídias 
visto que o filme é dedicado a ela, que faleceu durante esse período de realização do documentário. Há um momento do filme, em que o diretor recorda a morte de Stalin, quando ele tinha oito anos, e quase todos em sua casa choravam, exceto sua mãe, que apenas se matinha respeitosa. Dentro dessa perspectiva, o diretor parece sentir uma nostalgia, talvez associada aos tempos de seus avós, e cria um personagem ficcional, que vive no período da Rússia czarista, um tempo em que o país era poder e tinham a crença em Deus. E essa ausência de um Deus, de uma crença na União Soviética, talvez seja a grande crítica do diretor à política soviética. Segundo a historiadora Arlene Clemesha, a Rússia (no século XVII) constitui um dos maiores impérios do mundo. A causa da Rússia ter se tornado em uma grande potência foi o forte investimento na modernização do exército. Entre os séculos XVII a XIX, o país destinava seus recursos anuais a uma percentagem superior a 50\%, chegando a $85 \%$. Em relação ao período soviético, os avanços em busca da modernização e investimentos no setor militar ainda era a grande estratégia dos líderes, tanto que alguns historiadores chegam a encontrar um paralelismo entre Stalin e Pedro I, o Grande. Na opinião de Mikhalkov, os soviéticos estariam iludidos com toda a potência que União Soviética gozava naquele período

\section{DESEJOS E MEDOS DE ANNA}

BELO HORIZONTE

v. 19
Em 1980, aos seis anos de Anna, seu pai - que está por trás das câmeras - faz algumas perguntas simples a ela:

- Diga-me o que a amedronta mais?

- A Bruxa.

$[\ldots]$

- Qual é coisa que você mais quer?

- Um crocodilo.

- E o que você mais odeia?

- A sopa que chamamos de Bosrch.

A pequena Anna parece feliz, sorri muito, e suas respostas estão dentro do universo fantasioso das crianças. Porém, no ano seguinte, em 1981, com a entrada de Anna à escola, os desejos e medos passam a ser pensados no coletivo, no povo soviético, e não nos seus próprios desejos. Nesse momento, o pai aparece diante da câmera e vemos o diálogo dos dois. Anna responde: o que mais ama é a natureza, o que mais odeia é gente má, o que mais lhe amedronta são brigas e o que mais queria era ser inteligente. No entanto o pai questiona o que ela queria naquele momento, ela responde: "me comportar bem", a garota se sente envergonhada no momento em que o pai a desafia em sua resposta, se não seria nadar. Timidamente, ela responde que também. Anna se vai,

\section{Crítica Literária, outras Artes e Mídias}


corre em meio ao campo, e o pai recorda de sua infância, desabafa ao final dessa sequencia em voz-over, que esse medo de responder errado, de se sentir diferente dos demais também aconteceu em sua infância, em que era canhoto e fora forçado a ser destro, e como sofreu algumas dificuldades com isso na escola. Nesse instante do filme, podemos constatar como a política socialista influenciaria diretamente a vida pessoa de Anna, como todos seus desejos seriam reflexos dos ideais soviéticos.

Logo após essa sequência, o diretor realiza uma crítica social ao fazer uma montagem paralela, contrapondo imagen de arquivo de Brejnev e da a juventude comunista às imagens do povo pobre, cantando e dançando da rua, a maioria velhos em um vilarejo humilde, com roupas modestas embaixo de neve. Uma sequencia de imagens de um grande teatro lotado por pessoas bem vestidas cantando o hino internacional socialista, intercalada com as imagens das pessoas pobres dançando na rua, os aplausos à Bejnev são inseridos sobre as imagens dessas pessoas comuns. O diretor cria uma montagem dialética dessa forma, e deixa sua crítica ao socialismo de modo implícito, ao tirar os aplausos dos célebres e ao dá-los aos cidadãos comuns.

Essa utilização do material de arquivo de cunho institucional e propagandístico, juntamente com os desejos e medos de Anna, revela o poder da mídia e da TV em manipular o pensamento da população. O diretor registra como a opinião de sua filha é influenciada pela mídia, seja pela TV ou pelo jornal em que lê sobre a morte dos políticos. Durante sua infância, o diretor pode perceber a força dos meios midiáticos em sua vida, ao crescer, e estudar em outros países fez com que ele tivesse um olhar mais crítico sobre essa situação de manipulação ideológica da União Soviética. Isso de certa maneira, relaciona-se como a tecnologia em voga de cada geração. A partir desse ponto de vista, conforme Benjamin:

Somente um observador superficial pode negar que existem correspondências entre o mundo da tecnologia moderna e mundo arcaico dos símbolos da mitologia. Num primeiro momento, de fato, a novidade tecnológica produz efeito somente enquanto novidade. Mas logo nas seguintes lembranças da infância transforma seus traços. Cada infância realiza algo grande e insubstituível para a humanidade. Cada infância, com seus interesses pelos fenômenos tecnológicos, sua curiosidade por toda a sorte de invenções e máquinas, liga as conquistas tecnológicas aos mundos simbólicos antigos. Não existe nada no domínio da natureza que seja por essência subtraído de tal ligação. Só que ela não se forma na aura da novidade, e sim naquela do hábito. Na recordação, na infância e no sonho. ${ }^{8}$

À medida que Anna cresce, percebemos uma mudança tanto no tipo de roupa e como em sua visão político-ideológica.

$\begin{array}{lllllll}\text { EM TESE } & \text { BELO HORIZONTE } & \text { v. } 19 & \text { N. } 1 & \text { JAN.ABr. } 2013 & \text { VENTURA. } 0 \text { tempo como protagonista em Anna dos } 6 \text { aos } 18 \text { [...] } & \text { P. } 262-275\end{array}$

\section{Crítica Literária, outras Artes e Mídias}


Em 1987, o pai indaga à filha se ela está ciente das mudanças que estão acontecendo no país. A filha responde: A Perestroika. Nesse contexto, a Rússia se abriu à iniciativa privada. A roupa que Anna veste nessa tomada é diferente das anteriores, ela veste um moletom, essa mudança é evidente na vida de Anna e na sociedade em geral. Para ilustrar tal transformação, o diretor utiliza uma sequência onde Gorbachev aparece explicando o que é Perestroika, e a seguir imagens de mulheres dançando rock dos anos de 1980, imagens de teste para comercial e desfiles, concursos de beleza, mostram como o modelo da juventude soviética começa a mudar. Anna declara que a Perestroika é melhor e interessante, e exemplifica com as roupas, diz que as roupas que usava antes eram de qualidade inferior.

\section{TEMPO CRONOLÓGICO: O FIM DA UNIÃO SOVIÉTICA E DOS SONHOS}

A partir de 1982, a URSS enterra seus líderes em um tempo muito curto. O documentário retrata essas perdas e até a dissolução da União Soviética. Essa transição começa com a morte de Brejnev em 10 de novembro de 1982. Mikhalkov insere imagens do velório de Brejnev, a família do cineasta reunida assiste a essa imagens pela TV, Anna está vestida com uma roupa escura, parece estar em luto, a roupa é de uma tradicional aristocrata tradicional e carrega em seu peito um broche de estrela, ela parece estar muito comovida com a morte do líder de seu país, nesse momento, o diretor decide indagar sobre seus desejos e medos:

- O que mais você mais quer?

- Que o povo soviético sempre se lembre de Brejnev.

- O que mais lhe amedronta?

- Que haja uma guerra.

- O que você mais ama?

- Quando você está em casa.

- O que você mais espera?

$-\mathrm{O}$ ano novo.

A sequência posterior a esse diálogo é distinguida por planos que "ilustram" as festividades de final de ano, porém toda essa festividade é posta a baixo ao entrar as imagens subsequentes: mais um velório. A URSS enterra dessa vez Andropov (falecido em 9 de fevereiro de 1984). O diretor declara, em voz-over, que fora denunciado por estar realizando um filme clandestino. Então, para tomar certos cuidados, ele parece fazer as tomadas e o som sozinho em casa entrevistando a pequena Anna, que está mais uma vez comovida com a morte de mais um líder soviético. O diretor pede desculpas pela qualidade da imagem, por talvez não estar bem filmada. Anna diz que ama estar reunida em família, que

EM TESE

BELO HORIZONTE

v. 19

N. 1

JAN.-ABR. 2013

VENTURA. 0 tempo como protagonista em Anna dos 6 aos 18 [...]

P. 262-275

\section{Crítica Literária, outras Artes e Mídias}


odeia brigas de família e no mundo, e declara, que o que mais quer é que um bom líder seja escolhido e que este cuide bem deles (os soviéticos).

A sequência seguinte é também sobre um velório, a câmera registra as imagens do enterro de Chernenko (falecido em 10 de março de 1985). Nesse momento, o filme retrata o medo de instabilidade e incertezas no cenário político-social. Anna diz temer a guerra. Nesse contexto, ocorria guerra entre soviéticos e afegãos, que foi um conflito que durou nove anos, entre 1979 a 1988. A guerra se deu por tropas soviéticas invadirem o Afeganistão objetivando apoiar o governo marxista, e os insurgentes mujahidin afegãos procuravam derrubar o regime comunista no país.

Imagens censuradas de outro filme do diretor são inseridas para retratar como o governo silenciava o assunto guerra. Essas imagens são de soldados indo à guerra (ficcional) O diretor insere imagens de lápides, com fotos dos soldados impressas em granitos, mortos "por causa desconhecida". Em um desses enquadramentos, vemos um pombo em cima de uma dessas lápides sujas pelas fezes de uma ave. Tal plano seria uma crítica, que contrapõe à ideia desse heroísmo. O diretor exibe, na sequência posterior, imagens de túmulos, lápides e cidadãos comuns ou que tiveram alguma morte mais "honrada", porém, estes têm lápides mais simples, onde mal se consegue ler o nome da pessoa, e o diretor, em voz-over, declara que esses nomes (dos homens comuns) serão apagados da memória.

Gorbachev é eleito o novo líder em 1985 e, com ele, veio a abertura ao capitalismo na União Soviética. Ao implantar implanta a Glasnost, medida seguia o modelo de liberdade de imprensa e informação internacional, contribuiu para o declínio no socialismo. Jean Baudrillard crítica esse excesso de informação e transparência imposta pela mídia:

Não cessaremos de denunciar essa síndrome da informação, essa midiatização escandalosa e essa "liberação" no campo vazio da transparência. [...] A informação possui todos os direitos, posto que ela regulamenta o direito à existência. Assim, se exerce o farisaísmo odioso dos ocidentais: frente ao desmoronamento dos poderes do leste, nós nos convencemos que essa queda ocorre porque tudo isto contraria a lei da informação. Tudo isto, stalinismo, comunismo, socialismo, era no fundo irreal porque sub-exposto [sic] à luz da democracia e dos direitos dos homens. Hoje, enfim, tudo ascende à transparência da informação. Glasnost. ${ }^{9}$

O sonho comunista então começa a ruir. O diretor Mikhalkov retrata essa mudança ao inserir imagens das invenções bélicas/tecnológicas: aviões supersônicos, foguetes, armas nucleares. Enquanto isso, a força do fundamentalismo islâmico crescia, tinha como líder Aiatolá Khomeini. Com
9. BAUDRILLARD. Televisão/ revolução: O caso Romênia p. $147-8$ 
a falta de um herói, de um líder, igrejas e seus cultos passam ser a grande sensação no país. Imagens de cultos, devotos, desfiles de moda são mostradas, além dos caixões de vindos do acidente nuclear ocorrido em 1986 em Chernobil (Ucrânia, que na época era parte da União Soviética). Nesse instante do filme, o diretor que criticava o socialismo pass a criticar a Perestroika e todas as mudanças advindas dela.

\section{A AUTORREFERENCIALIDADE DE MIKHALKOV: TEMPO}

\section{SUBJETIVO}

Apesar do nome do documentário ser Anna dos 6 aos 18 e a proposta inicial do diretor ter sido registrar os medos e desejos de sua filha no decorrer dos anos, Mikhalkov fala muito mais de seu país e da URSS, traz reflexões e comentários sobre as mudanças ocorridas nesse período de vida de sua filha, além de realizar ao mesmo tempo, uma autoanálise na medida em que o filme desenrola. O filme parece perder um pouco o foco de sua proposta inicial, no momento em que passa a documentar a transição político-ideológica que a Rússia passa entre os anos de 1980 a 1991. Em 1988, com a morte da mãe do diretor Mikhalkov, o discurso dele, nesse momento, passa a ser sentimentalista e nostálgico. O diretor retoma o personagem Oblomov, insere algumas tomadas do filme em que o pequeno Oblomov está ao aconchego de sua mãe e, em seguida, sua mãe o leva para rezar numa capela. Desse modo, é possível identificar que o diretor, se identifica muito com esse personagem ficcional, podemos inferir que Oblomov poderia ser o alterego de Mikhalkov. Ou ainda, Mikhalkov se ficcionaliza em Anna dos 6 aos 18 por meio desse personagem. Assim, o diretor utiliza diferentes mecanismos para falar de si, ou seja, utiliza o outro para proferir seu próprio discurso ou chega a manipular todo um conjunto de materiais de arquivo, registros, para servirem como base para apoiar seus argumentos e sentimentos.

Essas estratégias e práticas discursivas parecem ter se tornado um fenômeno recorrente na contemporaneidade, diversas formas de expressões artísticas têm adotado com muita frequência a utilização da primeira pessoa. Hoje, no século XXI, essa estratégia narrativa se difundiu, invadiu práticas cotidianas, aliada às novas tecnologias e às redes de sociabilidade virtuais. Vale destacar a evolução das ferramentas de comunicação como telefone celular, correio eletrônico e a grande popularização dos chats na década de noventa do século passado até o atual "boom" das redes de sociabilidade. Sites de diferentes natureza e finalidade também compartilham informações e arquivos pessoais, como fotos e vídeos.

No entanto, a autorreferencialidade, entendida como uma modalidade da "escrita de si", não é um fenômeno da atualidade. Desde o período clássico, filósofos como Platão e Xenofonte constituíram relatos não só de seus pensamentos, mas também de suas vidas. Foucault, em sua pesquisa
EM TESE
BELO HORIZONTE
v. 19
N. 1
JAN.-ABR. 2013
VENTURA. 0 tempo como protagonista em Anna dos 6 aos 18 [...]
P. 262-275

\section{Crítica Literária, outras Artes e Mídias}


10. MIRANDA. Corpos Escritos, p. 27.

11. MIRANDA. Corpos Escritos, p. 27.

12. AZEVEDO. Autoficção e literatura contemporânea, p. 26. arqueológica sobre a "estética da existência", analisa, além da cultura greco-romana dos primeiros Impérios, textos antigos de Atanásio (séc. IV a. C.) que mostram que as "escritas do eu" funcionavam como uma força autocoercitiva, pois "ao escrever sobre os movimentos da alma, [o sujeito] passa a conhecer-se e, ao se conhecer, passa-se a ter vergonha de si e armar-se contra o pecado". ${ }^{10}$ Escrever sobre si implicava uma espécie de autoanálise moral, conhecer-se e refletir sobre os próprios atos. Em diversos momentos do filme, podemos constatar falas de autoanálise ou autocrítica do pai/diretor Mikhalkov. Como em: "Esta resposta terrível e inesperada, mostrava que o império começara a apoderar-se do ego dela mas não dei atenção a isto então".

A autorreferencialidade, embora menos corrente na Idade Média, era utilizada pelos trovadores que se valiam dessas estratégias discursivas para declarem seus sentimentos às jovens pastoras, em suas cantigas de amigo. Com a ascensão da burguesia, no mundo moderno, o individualismo encontrou "na autobiografia um dos meios mais adequados de manifestação". ${ }^{11}$

A autobiografia pode ser também "uma manifestação de angústia ligada ao enfraquecimento ou à perda de identidade, em virtude da incerteza hodierna própria à relação eu-outro". ${ }^{12}$. Essa sensação de angústia pode ter sido o motivo da escrita de Ecce Homo de Nietzsche, em 1888, texto que, além de mostrar a intimidade do filósofo, ocupa-se de sua imagem no mundo: "Eu sou um aprendiz do filósofo Dionísio, e faço mais gosto em ser tomado como sátiro do que santo" (NIETZSCHE, 1995, p. 17). Passado mais de um século, ta fenômeno tornou-se não apenas em uma necessidade frente às angústias existenciais, mas também um hábito de autoexibição cotidiana, e as redes de comunicação são as responsáveis por difundir as intimidades.

Nos últimos decênios, podemos verificar a presença de obras literárias autoficcionais como: Fils (1977), de Doubrosvky; O falso mentiroso (2004) e Histórias mal contadas (2005), de Silviano Santiago; Nove noites, de Bernardo Carvalho (2002), entre outras. É possível constatar também o grande aumento tanto na produção como na venda de obras autobiográficas e biográficas no mercado editorial. Não apenas na literatura, as narrativas de si tornaram-se mais recorrentes, podemos notar esse aumento no audiovisual. Nos últimos dez anos, temos alguns exemplos de filmes nacionais com esse viés. ${ }^{13}$

Mesmo Anna dos 6 aos 18 ter sido lançado no ano de 1993 e por tratar acontecimentos históricos datados como a Guerra Fria e a queda do Muro de Berlim, o filme lida com questões universais, como relação de pai e filha, relações familiares, sentimentos de perda, medo da guerra e incertezas do futuro. Conforme Jean-Claude Bernardet,
13. Um passaporte húngaro (2003) de Sandra Kogut; 33 (2003), de Kiko Goifman; Clarita (2007), de Thereza Jessouroun; Diário de Sintra (2007) de Paula Gaitán; Santiago (2005), de de Familia (2009), de Waum de Familia (2009), de Wallace de Carlos Dorangreen (2009) Canoa Quebrada Rodrigues; Canoa Quebrada (2010), de busca (2010) de Flávi Castro. Elena (2012) de Petra Castro; Otto (2012) de Petra Costa; Os dias com (2012) de Cao Guimaráes, S dias com elé (2012) de Maria Clara Escobar. Também vale destacar alguns estrangeiros como: Tarnation (2003), de Jonathan Caouette, e Les Plages
d'Agnès (2008), de Agnès Varda.

EM TESE $\quad$ BELO HORIZONTE $\quad$ v. $19 \quad$ N. $1 \quad$ JAN.-ABr. $2013 \quad$ VENTURA. 0 tempo como protagonista em Anna dos 6 aos $18[$ [...] $\quad$ P. $262-275$

\section{Crítica Literária, outras Artes e Mídias}


14. BERNARDET. Documentários de busca: 33 e Passaporte Húngaro, p. 89. esses filmes vivem essa tensão de documentário com desejos de ficção e de uma ficção com desejos de realidade. São filmes extremamente ricos justamente por isso, e que, nesse sentido, expressam uma subjetividade tal como muitos de nós a vivenciam atualmente. Não mais uma subjetividade como individualismo, mas como uma subjetividade dinâmica, que não sabe em que medida é íntima ou em que medida é produto da sociedade. ${ }^{14}$

Dessa forma percebemos o entrecruzamento entre público e privado na vida e Anna, como os acontecimentos político-sociais interferem na vida íntima de Anna. Da mesma forma, na medida em que Mikhalkov avança com sua estrutura fílmica, é possível notar como o diretor diz cada vez mais de si e de suas angústias, seja por meio dos acontecimentos políticos, seja por meio de sua filha ou família. Em determinado momento, Mikhalkov percebe a existência de um distanciamento entre ele e sua filha:

Falando com minha filha, eu descobri, com lucidez aterradora a distância que agora nos separava, as fechaduras que ela havia forjado e as chaves que ela não me dera a ninguém, nem a mim, seu próprio pai. Meu Deus, eu pensei! Foi ela que alguns anos atrás, quase ontem, escondia o sorriso e dizia que tinha medo de bruxa, que odiava borsche que queria um crocodilo? Tinha sido tão fácil tirar dela o direito de rir sem razão, falar bobagens sem ter reprimendas!
Essa autoanálise ou reflexão de Mikhalkov revela um momento de crise, uma crise do $e u$, do pai e diretor. O pai percebe que a filha cresceu, passou a ter outros referenciais e outros valores relacionados a sua geração.

Para concluir, podemos observar que a forma do filme construída por meio de materiais de arquivo, tanto público como privado, demonstra não apenas as transformações político-sociais da Rússia, como da vida de Anna e Mikhalkov. Ao longo do filme, o diretor se coloca numa postura crítica em relação à União Soviética, manifesta um certo saudosismo de uma época em que não viveu: czarismo. No entanto, as transformações ocorridas no processo de queda do socialismo e ascensão da social democracia pós-muro, queda do muro de Berlim (seguindo a lógica capitalista) não garantiu o esperado retorno de bem-estar social. Todavia a democracia não pode necessariamente garantir que seus cidadãos sejam felizes, prósperos, sábios, pacíficos ou justos. É importante ressaltar ainda que, por ser um cineasta reconhecido e vindo de uma família oligarca pré-socialista soviética, pertencente a uma classe social intelectual durante todo regime soviético, pôde se tornar um observador privilegiado desse sistema. Assim, o diretor, aborda essas transformações ao retratar o capitalismo no seu perfil mais degradante. Mikhalkov parece desiludido e desesperançado como o novo regime político-econômico. As imagens que insere nesse momento são

EM TESE

BELO HORIZONTE

v. 19

N. 1

JAN.-ABR. 2013

VENTURA. 0 tempo como protagonista em Anna dos 6 aos $18[\ldots]$

P. 262-275

\section{Crítica Literária, outras Artes e Mídias}


apropriações da TV daquele contexto (final dos anos de 1980 e início dos anos de 1990), e/ou de seus acervos particulares documentais, revela, assim, uma Rússia tomada por uma epidemia demagogo-capitalista que subjugou os sonhos de liberdade de pensamento, crenças religiosas, opções políticas e liberdade de expressão. Ao representar as mudanças em seu país, o sonho e a realidade parecem não corresponder ao esperado, como declara em outro momento: "transformamos a vida em seriado de TV, a morte em jogo de computador e a aquisição em destruição", a política naquele atua momento da Rússia parece não corresponder ao seu ideal, o mundo lhe parece artificial, diferente daquele tempo e espaço em que sua família se reunia no interior, na sua infância em um ambiente rural.

Dessa forma, podemos verificar que, apesar do diretor seguir uma ordem cronológica, no que diz respeito ao crescimento de sua filha Anna e no desenrolar dos acontecimentos político-sociais, Mikhalkov oscila em alguns momentos os tempos, realiza alguns flash-backs, insere materiais de arquivo para dizer de um tempo em que vivenciou sua infância e juventude, além de trazer materiais ficcionais (como Oblomov) para tratar de um tempo subjetivo (seus sonhos, lembranças e saudosismos de uma época passada).

\section{REFERÊNCIAS}

ARFUCH, Leonor. La vida como narración. In.: El espacio biográfico: dilemas de la subjetividad contemporánea. Buenos Aires: Fondo de Cultura Econ. Argentina, 2002.

AZEVEDO, Luceine de Almeida. Autoficção e literatura contemporânea. Uberlândia, MG, 2008, In: Revista Brasileira de Literatura Comparada n. 12 , p. 31-4.

BAUDRILLARD, Jean. Televisão/revolução: O caso Romênia. In: PARENTE, A (org.). Imagem máquina: A era das tecnologias do virtual. Rio de Janeiro: Ed. 34, 1993.

BENJAMIN, Walter. Passagens. Belo Horizonte: UFMG, 2006.

BERNARDET, Jean-Claude. Documentários de busca: 33 e

Passaporte Húngaro. In: LABAKI, Amir e MOURÃO, Maria Dora. o Cinema do Real. São Paulo: Cosac Naify, 2005.

CLEMESHA, A. E. A Rússia Czarista. História Viva (Edição Especial), v. 18, p. 14-9, 2008

DERRIDA, Jacques. Mal de arquivo: um a impressão freudiana Trad. Cláudia de Moraes Rego. Rio de Janeiro: Relume Dumará, 2001

DIDI-HUBERMAN, George. Cuando las imágenes toman posición. Madrid: A. Machado, 2008.

DIDI-HUBERMAN, George. Imágenes pese a todo: memória visual del holocausto. Barcelona: paidós, 2004.

\section{Crítica Literária, outras Artes e Mídias}


LINS, C.; REZENDE, L. O audiovisual contemporâneo e a criação com imagens de arquivo. In: FABRIS, M., SOUZA G., FERRARAZ,

R., MENDONCCA, L., SANTANA, G. (Orgs) Estudos de cinema

e audiovisual. X Encontro Anual da Socine 2010. São Paulo:

Socine, 2010, p. 587-98.

LISSOVSKY, Maurício. Quatro + uma dimensões do arquivo.

In: MATTAR, Eliana (Org.). Acesso à informação e política de

arquivos. Rio de Janeiro: Arquivo Nacional, 2004, p. 47-63.

MIKHALKOV, Nikita. Anna dos $\mathbf{6}$ aos 18. Trad. Fabiano Ferreira. Rússia/França. 1994 [1993]. (100 min): 35mm, son., color.

MIKHALKOV, Nikita. Alguns dias na vida de Oblomov. Rússia. 1979. (135min): $35 \mathrm{~mm}$, son., color.

MIRANDA, Wander Melo. Corpos Escritos: Graciliano Ramos e Silviano Santiago. São Paulo: USP; UFMG, 1992.

NIETZSCHE, F. Ecce homo. Trad. de Paulo César de Souza, São Paulo: Companhia das Letras, 1995

RANCIĖRE, Jacques. A partilha do sensível: estética e política. Trad. Mônica Costa Netto. São Paulo: EXO Experimental / Editora 34, 2005.

SOUZA, Eneida Maria de. Janelas indiscretas: ensaios de críticabiográfica. Belo Horizonte: UFMG, 2011. 